\title{
An Evaluation of the Participatory Learning and Action (PLA) Training Workshop
}

\author{
Mahmoad H. Ibnouf ${ }^{1}$, Maen N. Sheqwarah ${ }^{2} \&$ Kamel I. Sultan ${ }^{2}$ \\ ${ }^{1}$ Faculty of Agriculture, University of Bahri, Khartoum, Sudan \\ ${ }^{2}$ Department of Agricultural Economics and Extension, Faculty of Agriculture, Jarash University, Jarash, Jordan \\ Correspondence: Mahmoad H. Ibnouf, Faculty of Agriculture, University of Bahri, Khartoum, Sudan. Tel: \\ 249-911-862-650. E-mail: ibnouf337@gmail.com
}

$\begin{array}{cc}\text { Received: August 30, } 2015 & \text { Accepted: September 29, } 2015 \quad \text { Online Published: November 15, } 2015 \\ \text { doi:10.5539/jas.v7n12p144 } & \text { URL: http://dx.doi.org/10.5539/jas.v7n12p144 }\end{array}$

\begin{abstract}
The main objective of this study was to evaluate the perception of the trainees regarding the participatory learning and action training workshop which was held at Edamer Local Implementation Unit during the period of July 17-25/2011. The participants of the training workshop were selected individuals and groups. Twenty four trainees attended the training workshop. The questionnaire was developed by the researchers and covered selected statements related to perceptions of the trainees regarding overall activities of the training program. The data was collected from the trainees at the end of the training program. Information obtained from the questionnaires analyzed using the Statistical Package for Social Sciences (SPSS), means and standard deviation were used as statistical methods to determine the perceptions level of the trainees.

The results of the study indicated that the trainees as a group agreed that the training program was very useful and interesting. They also indicated that the trainer was very friendly, helpful and used a variety of teaching methods and field work techniques. The results also indicated that the training program covered required technical and professional competencies in participatory learning and action approach. The study produced some recommendations and strategies for improving the present and future program.
\end{abstract}

Keywords: participatory learning, action, approach, PLA, Edamer, watershed, Nile Basin, technical competencies, training program

\section{Introduction}

Participation define as a process in which a group or groups of exercises initiative in taking action, stimulated by their own thinking and decision making, and over which they have specific controls (Tandom, 1998). The traditional meaning of training has been the transfer of knowledge and expertise from the trainer to the learner, where the trainer defines what particular set of knowledge and expertise are needed to learn. This approach to training believes that trainers know everything, and the learner is considered as an empty container to be filled up by the trainer. Learners play a passive role and are bound to learn what the trainer teaches. Participatory training views training not as a transfer of "knowledge and expertise" but as a process of growth and discover, aimed not just at "knowing more" but behaving differently. The focus is on building up ones critical consciousness; on examining one's values, attitudes and orientations; on unfreezing set of notions and set of patterns of behavior; and questioning, rethinking and re-learning. It is this view of training as a learning process-learning new skills, concepts and behavior which practice in participation focuses on this thematic area (Kirk Patrick et al., 2005; Andria, 2008).

The participatory training is an educational strategy in which learners are active participants in the educational process, and their needs and questions, their reflection and analysis, and their strategies for change to carry the process forward. This approach to training aims at freeing people from patterns of thinking imposed upon them by dominant focuses, such approach should help to build in more confidence in their competencies. Its methodology is learner-centered, experience-based and open-ended. Participatory training contributes in enhancing observation and analytical skills of learners and has been effective in preparing people for bringing change in their lives for betterment. It strengthens people's understanding that change is possible within one's self and at the level of the group (Tandom, 1998; Bhandari, 2003; Mwanyumba, 2010; Ibnouf, 2014). 
The Eastern Nile Watershed Management Project (ENWMP) is one of the Nile Basin Initiative (NBI) projects. The main objectives of the community watershed management component are to promote wider adoption of sustainable land water management practices and technologies, and increase agricultural productivity (Ministry for Foreign Affairs-Finland, 2010). The philosophy of this project is to adopt the participatory training approach to enhance the capacity of the field staff and the stakeholders. Participatory training is used in the process of adult education to effectively applying the communication and facilitation skills to help local communities to identify their needs and problems.

\subsection{Statement of the Problem}

The personnel of the Watershed Management Project (WMP) are the major resource for sustainable development in the project area. The project's success depends to a large extent on their level of competencies. Whether they are administrators, technical assistance, or counterparts this personnel must possess two broad areas of competencies. Technical competencies related to different components of the project as a general subject or at some degree of specialization in one of its fields. The professional competencies related to the concepts, principles, methods, and approaches of planning, implementation and the evaluation of extension or rural development programs. In addition to communication and facilitation skills and approaches to change the behaviors and attitudes of the target groups (Ibnouf, 2015).

According to Laxer (2010) the training needs assessment of the whole Sudan component of the ENWMP project team and its counterparts was conducted as a self-assessment activity where the respondents were requested to fill in a standard matrix form. The training needs assessment target the project management staff persons, its Sudanese technical assistance experts as well as the project counterparts. Based on the results of this assessment it would appear that the focus of the project capacity building and training events for the project personnel and the stake holders should be on the skills related to the use of participatory approaches. It is important to realize that participatory training is not just a set of techniques, it functions in a certain historical socio-political context. The ideological bias of the participatory training needs to be understood clearly, it must be recognized that the role of the participatory training in bringing about change has some limitations. Firstly, structures and systems of society do not change within the training programs. Individuals can understood the social dynamics and the social change, their potential role in the process of change. Groups can learn how to function as an effective unit for action, and groups can experience a microcosm. Secondly, while working towards the change with poor, and illiterate people there is a great temptation to define change for them. As such, the educational intervention basically mobilizes support for a particular cause that consider right (Tandom, 1998).

\subsection{Purpose and Objectives}

The main purpose of this study was to assess the perceptions of the trainees regarding the participatory learning and action training workshop which was held at Edamer Local Implementation Unit (LIU), on July 17-25, 2011, using a summative evaluation type, which assesses the worth of the workshop activities (Taylor, 1974). More specifically the objectives of the study were as follows:

1. To evaluate the weaknesses and strengths of the training program as perceived by the trainees.

2. To determine the level of agreement of the trainees regarding different component of the training program.

3. To provide feedback for developing more effective future training programs.

\subsection{Description of the Training Workshop}

According to Abderhman (2011), the main objective of the training workshop was to enhance the abilities of the participants on the utilization of the participatory approaches and tools to facilitate community based development process. The specific objectives were as follows:

1. To understand the principles of the Participatory Learning and Action (PLA) approach.

2. To apply the PLA tools and techniques to facilitate situational analysis and gap identification.

3. To orient the participants on the shortcomings of PLA.

4. To expose the participants to have a feeling of how PLA can be used or applied in the field.

Table 1 shows the summary of the training workshop contents as demonstrated by Abderhman (2011).

The main training methods and techniques used in the training workshop are summarized as follows:

1. Lecture, open discussion and group discussion.

2. Brainstorming and revision of the group work. 
3. Exchange of experience and opinion.

4. Data show and fillip chart.

5. Field work and feedback on field work.

Table 1 . The training workshop contents

\begin{tabular}{ll}
\hline Title & Contents \\
\hline Introduction to PLA & - Concept of community development and participation. \\
& - Emergence and evolution of participatory approaches. \\
& - Concept of PLA, its uses, strengths and shortcomings. \\
Participatory research plan & - Design a participatory research plan. \\
design and tools & - Introduction and classification of PLA tools. \\
Skills of PLA practitioner & - Introduction to PLA skills such as questioning skills, \\
& listening skills and nonverbal communication skills. \\
General tools & - Introduction to PLA general tools: Secondary data, direct \\
& observations and semi structured interviews. \\
Time study tools & - Introduction and practice on: Time line, trend analysis, \\
Space study tools & - Introduction and practice on resources and services map, \\
Ranking tools & social map and mobility map. \\
& - Introduction and practice on: Preference ranking, \\
Analysis tools & direct matrix ranking and pair-wise ranking. \\
Preparation for field work & - Introduction and practice on: Problem analysis (problem tree). \\
& - Rules of different team leaders and team members. \\
Field work & - Technical and logistical support for the field work. \\
Feedback from the field work & - Conduct PLA in three selected sites. \\
Wrap up and closure & - Prepare report on field work events. \\
& - Review training contents. \\
& - Evaluate the training workshop. \\
\hline &
\end{tabular}

\section{Methodology}

\subsection{Participants}

The participants of the training workshop were selected individuals and groups from the National Project Co-ordination Unit (NPCU), Edamer Local Implementation Unit (LIU), Stakeholders, Non-Governmental Organizations (NGOs) and communities representatives. Twenty four trainees attended the training program during the period of July 17-25, 2011. All the trainees completed the questionnaire. Table 2 shows the distribution of the trainees by gender.

Table 2. Distribution of the trainees by gender

\begin{tabular}{llll}
\hline Institutions & Male & Female & Total \\
\hline NPCU & 1 & 0 & 1 \\
Eldamer LIU & 8 & 4 & 12 \\
Stakeholders & 2 & 3 & 5 \\
Communities representative & 3 & 2 & 5 \\
NGOs & 0 & 1 & 1 \\
Overall total & 14 & 10 & 24 \\
\hline
\end{tabular}




\subsection{Development of the Questionnaire}

The questionnaire was developed by the researcher and covered selected statements related to perceptions of the trainees regarding overall activities of the training program. Likert - type scale was used as follows: strongly agree $=5$, agree $=4$, fair $=3$, disagree $=2$, strongly disagree $=1$.

\subsection{Data Analysis}

The data collected from the trainees at the end of the training program. The trainees completed the questionnaires. Information obtained from the questionnaires analyzed using (SPSS), means and standard deviations were used as the statistical methods to determine the perceptions level of the trainees.

\section{Results and Discussion}

The trainees were asked to evaluate (15) different statements regarding the overall activities of the training program. The statements were rated on 1-5 point scale. Table 3 shows the means and standard deviations for the perceptions of the trainees regarding the training program.

As a group the trainees tended to agree on all the statements. The following list is a summary of the highest rated statements: (total mean scores 4.00 or higher on a 1-5 point scale).

A. The training program was designed according to the respondents specific needs and self-assessment activity (4.83).

B. The trainer was well organized on both professional and technical competencies (4.83).

C. The trainer used different and effective training methods and techniques (4.78).

D. The trainer was friendly and helpful (4.75).

E. The training program covered different knowledge and skills related to the approach (4.66).

F. The training program was useful and attractive (4.66).

G. The training program covered the theoretical framework of the approach (4.56).

H. Adequate time was given to the practical component of the training program (4.54).

I. The training hall was appropriate and comfortable (4.50).

J. The training program was designed according to my expectations (4.45).

$\mathrm{K}$. The practical component of the training program was useful and appropriate (4.39).

L. The training period was appropriate (4.31).

M. The participation level of the trainees was very high on both theoretical and practical competencies. (4.29).

$\mathrm{N}$. The commitment of the trainees was carried out according to the planned schedule (4.16).

On the other hand, only one statement received a rating less than (4.00). This statement is: "the services provided were appropriate (3.87).

In summary, the trainees indicated that the training program was worthwhile program and important to them, and covered all technical and professional competencies related to the participatory leaning and action approach. They also indicated that the trainer was very friendly, helpful and used a variety of teaching methods and field work techniques. The study revealed that further adequate time was given to practical and field work activities. These results are similar to the results of the evaluation of the baseline survey workshop (Ibnouf, 2011) and generally tended to support the findings of other studies. 
Table 3. Means, standard deviations and ranking, for the perceptions of the trainees regarding the training program

\begin{tabular}{|c|c|c|c|}
\hline Rank & Statement & Valid cases & Mean/standard deviation \\
\hline 1 & The training program was designed according to my training needs & 24 & $4.83 / 0.48$ \\
\hline 1 & The trainer was well organized & 24 & $4.83 / 0.48$ \\
\hline 2 & $\begin{array}{l}\text { The trainer used different and effective training methods and } \\
\text { techniques }\end{array}$ & 23 & $4.78 / 0.51$ \\
\hline 3 & The trainer was friendly and helpful & 24 & $4.74 / 0.53$ \\
\hline 4 & $\begin{array}{l}\text { The training program covered different knowledge and skills related } \\
\text { to the approach }\end{array}$ & 24 & $4.66 / 0.56$ \\
\hline 4 & The training program was useful and attractive & 24 & $4.66 / 0.56$ \\
\hline 5 & $\begin{array}{l}\text { The training program covered the theoretical framework of the } \\
\text { approach }\end{array}$ & 23 & $4.56 / 0.56$ \\
\hline 6 & $\begin{array}{l}\text { Adequate time was given to the practical component of the training } \\
\text { program }\end{array}$ & 22 & $4.54 / 0.67$ \\
\hline 7 & The training hall was appropriate and comfortable & 24 & $4.50 / 0.58$ \\
\hline 8 & The training program was designed according to my expectations & 24 & $4.45 / 0.58$ \\
\hline 9 & $\begin{array}{l}\text { The practical components of the training program was useful and } \\
\text { appropriate }\end{array}$ & 23 & $4.39 / 0.78$ \\
\hline 10 & The training period was appropriate & 22 & $4.31 / 0.83$ \\
\hline 11 & The participation level of the trainees was very high & 24 & $4.29 / 0.85$ \\
\hline 12 & $\begin{array}{l}\text { The commitment of the trainees was carried out according to the } \\
\text { planned schedules }\end{array}$ & 24 & $4.16 / 0.76$ \\
\hline 13 & The services provided were appropriate & 24 & $3.87 / 1.15$ \\
\hline
\end{tabular}

\section{Conclusions and Recommendations}

\subsection{Conclusions}

Based on the finding of this study the following conclusions are drawn:

(a) The trainees as a group agreed that the training program was very useful and interesting.

(b) The trainer was very friendly, helpful and well organized.

(c) The training program was worthwhile, important and designed according to the needs of the trainees.

(d) The training program covered the required technical and professional competencies in the participatory leaning and action approach (PLA).

(e) The trainer used a variety of teaching methods and field work techniques.

(f) Adequate time was given to the practical and field work activities

In addition to that specific conclusions, general conclusions can be made as the following:

1. New confidence.

2. New positive social and political relationships.

3. New technical, political and professional competencies.

4. New organization and management abilities and capabilities.

\subsection{Recommendations}

The following are some recommendations and strategies for improving the present and future training program of the CWMP:

A. Since the CWMP is a Technical Assistances (TAs) oriented project, it is recommend that all the future training programs are to be organized and conducted by the TAs team. This is because they are aware about the 
needs, interests and problems of the watershed communities, stakeholders and counterparts. They also interact closely and contribute to the success of different activities of the project.

B. Greater collaborative effort should be made among the project team in Edamer, Dinder and Bau. Cooperation and sharing of expertise, ideas and facilities would help to improve the effectiveness of the future training programs of the project.

C. The project team should continue to develop and enlarge follow-up survey to determine the effectiveness of this training program.

D. The emphasis of the proposed follow-up survey should not merely be on (knowing) but rather on (making use of what is known).

E. Certain communication and facilitation competencies are required for success farming and rural development activities. The most important competencies have implications for the project team for present and prospective watershed development activities.

F. A follow-up survey should be considered by the project team to determine the participation level of the former trainees in the project activities. The follow-up survey should be organized on continues basis to meet the problem of the former trainees.

G. The results of this study should be shared with the trainees, trainer, stakeholders and the administrators of the CWMP.

\section{References}

Abderhaman, A. A. (2011). Training workshop proposal on PLA. ENWMP, Khartoum, Sudan.

Andria, A. (2008). Evaluation of training programs for rural development. Journal of Applied Quantitative Methods, 3(2), 139-150.

Bhandri, B. B. (2003). Participatory rural appraisal, institute for global environment strategies. Kanugawa, Japan.

Ibnouf, M. H. (2014). Participatory analysis of the constraints to adoption and diffusion of artificial insemination in dairying in lower Atbra River Area. University of Khartoum Journal of Veterinary Medicine and Animal Production, 5(1).

Ibnouf, M. H. (2015). Evaluation of a training program in communication skills from prospective of livestock facilitators in Toker area. Journal Economic and Social Studies, 5(1), 81-89.

Kirkpatrick, L. D., \& Kirkpatrick, D. J. (2005). Evaluating training programs: The four Levels. Berrett Koehler Publishers Inc., California, USA.

Laxen, J. (2010). Training needs assessments and project training plan for 2010-2011. ENWMP, Khartoum, Sudan.

Ministry for Foreign Affairs-Finland. (2010). Bilateral Finland - Sudan technical assistance with the framework of ENWMP (Program Document). Addis Ababa, Ethiopia.

Mwaynumba, P. (2010). Participatory analysis of the Farming system and resources in Wundayni Location, Tail District, Kenya. Livestock Research for Rural Development, 22(2).

Tandom, R. (1998). A manual for participatory training methodology in development. The Society for Participatory Research in Asia, New Delhi, India.

Tyler, R. (1974). Basic Principles of Curriculum and instruction. University of Chicago press. Chicago, IL, USA. 


\section{Appendix}

Appendix 1. The questionnaire of the training workshop

\begin{tabular}{|c|c|c|c|c|c|c|}
\hline No. & Statement & Strongly agree & Agree & Fair & Disagree & Strongly disagree \\
\hline 1 & $\begin{array}{l}\text { The training program was designed according } \\
\text { to my training needs }\end{array}$ & & & & & \\
\hline 2 & $\begin{array}{l}\text { The training program covered different } \\
\text { knowledge and skills related to the approach }\end{array}$ & & & & & \\
\hline 3 & $\begin{array}{l}\text { The training program covered the theoretical } \\
\text { framework of the approach }\end{array}$ & & & & & \\
\hline 4 & $\begin{array}{l}\text { Adequate time was given to the practical } \\
\text { component of the training program }\end{array}$ & & & & & \\
\hline 5 & The training period was appropriate & & & & & \\
\hline 6 & $\begin{array}{l}\text { The practical component of the program was } \\
\text { useful and appropriate }\end{array}$ & & & & & \\
\hline 7 & $\begin{array}{l}\text { The training program was useful and } \\
\text { attractive }\end{array}$ & & & & & \\
\hline 8 & $\begin{array}{l}\text { The commitment of the trainees was carried } \\
\text { out according to the planned schedules }\end{array}$ & & & & & \\
\hline 9 & $\begin{array}{l}\text { The participation level of the trainees was } \\
\text { very high }\end{array}$ & & & & & \\
\hline 10 & The trainer was friendly and helpful & & & & & \\
\hline 11 & The trainer was well organized & & & & & \\
\hline 12 & $\begin{array}{l}\text { The trainer used different and effective } \\
\text { training methods and techniques }\end{array}$ & & & & & \\
\hline 13 & $\begin{array}{l}\text { The training hall was appropriate and } \\
\text { comfortable }\end{array}$ & & & & & \\
\hline 14 & The services provided were appropriate & & & & & \\
\hline 15 & $\begin{array}{l}\text { The training was designed according to my } \\
\text { expectations }\end{array}$ & & & & & \\
\hline
\end{tabular}

Note. Please tick the response which best describe your situation.

\section{Copyrights}

Copyright for this article is retained by the author(s), with first publication rights granted to the journal.

This is an open-access article distributed under the terms and conditions of the Creative Commons Attribution license (http://creativecommons.org/licenses/by/3.0/). 